\title{
Análisis Crítico del Discurso de un actante ilocutivo de la novela The Help, escrita por Kathryn Stockett
}

\author{
Critical Discourse Analysis of an ilocutive agent of the \\ Novel The Help by Kathryn Stockett
}

Regina de las Mercedes Constantin Agramonte $\square$

Universidad de La Habana. Ciudad Habana, Cuba

\begin{tabular}{llll}
\hline Recibido: 15/08/2019 & Revisado: 15/11/2019 & Aceptado: 21/01/2020 & Publicado: 18/06/2020
\end{tabular}

\section{RESUMEN}

El objeto de estudio de este trabajo es la ideología feminista negra en el discurso literario. El objetivo es determinar cómo el discurso de un actante ilocutivo refleja un cambio en la ideología de las mujeres afroamericanas en el sur de los Estados Unidos durante los años 60. Se caracteriza además al actante ilocutivo como sujeto valorador. La investigación realiza un recorrido por la historia de los afroamericanos en los Estados Unidos desde el siglo XVII hasta el siglo XX para situar la novela en un contexto histórico concreto. Se desarrolla la base teórica de la investigación, que incluye el discurso, el análisis crítico del discurso, el discurso feminista negro y la modalidad para realizar un primer acercamiento al análisis crítico del discurso de un actante ilocutivo de la novela The Help, obra que describe la situación de las mujeres afroamericanas en Mississippi, Estados Unidos, durante la década de los años 60 en el contexto del Movimiento de los Derechos Civiles. Para ejecutar estas tareas se utilizaron los métodos de revisión de la literatura especializada, histórico-lógico, inductivo-deductivo, análisis literario, análisis crítico del discurso, y analítico-sintético. Los primeros resultados mostraron a un actante que se autovalora en su discurso como miembro de la comunidad de domésticas de manera positiva y asertiva, mientras que en su relación matrimonial se valora de forma negativa. Emite valoraciones negativas hacia todo lo que considere incorrecto en su contexto de manera desbordada.

Palabras clave: Análisis crítico del discurso, autodefinición, autovaloración, ideología, feminismo negro, modalidad.

\begin{abstract}
The black feminist ideology in literary discourse is the object of study of this research, which is aiming at determining how the discourse of an ilocutive agent reflects the change of ideology of Southern African-American women in the 1960s. Then, the characterization of the ilocutive agent as valuating subject is carried out. This research analyzes the novel The Help. Written by Kathryn Stockett, this novel describes the situation of AfricanAmerican women in Mississippi during the Civil Rights Movement. An ilocutive agent of the novel was chosen to critically analyze her discourse. Theory involving discourse, Critical
\end{abstract}


Discourse Analysis, black feminist ideology, and modality was presented in the research. The methodology included a literary review, the historical- logical, the inductive-deductive, analytic-synthetic methods, a literary analysis and a Critical Discourse Analysis. The results have shown that the ilocutive agent has positive and assertive self-valuations as a member of the community, whereas regarding her marriage the valuations are negative. The valuations are also negative and the ilocutive agent is gushing when she says her opinion on the context she is living.

Keywords: Critical discourse analysis, self-definition, self-, ideology, black feminism, modality.

\section{INTRODUCCIÓN}

El lenguaje desempeña un papel importante en la socialización, en la transmisión de conocimientos y valores, y en la toma de conciencia, aceptación o rechazo a la estructura social de la cual forma parte el ser humano. El discurso es una práctica social donde en un contexto sociocultural histórico concreto específico, la identidad de la persona se pone de manifiesto. Es expresión de su individualidad, así como de su pertenencia o no a ciertos grupos a partir de las ideas, creencias $u$ opiniones que comparte o no con ellos. Por tanto, el discurso como proceso del uso del lenguaje puede reflejar y moldear el orden social. Conforma y es producto de la interacción del individuo con la sociedad. Los sistemas de valores (relacionados con la cultura, la política, la economía, la ética, la estética o la religión) adquiridos durante esta interacción conforman la ideología del sujeto enunciador, que se expresa y reproduce mediante el discurso.

La ideología define quiénes somos como miembros de un grupo determinado y al mismo tiempo refleja y defiende los intereses, valores y objetivos principales de ese grupo (Van Dijk, 1993). Las ideologías son el fundamento detrás del juicio y la acción. Legitiman las acciones de los grupos sociales y organizan sus actitudes con respecto de temas sociales relevantes. Además, las ideologías pueden ocultar la verdad e impedir el reconocimiento de la realidad; por lo tanto,

permiten la legitimación del poder y de la desigualdad (Van Dijk, 1998). Sin embargo, también invisten de poder a los grupos dominados, crean solidaridad, y permiten la organización de la lucha.

Los miembros de un grupo comparten opiniones sobre experiencias y conflictos en común (representaciones sociales) y comparten un sentimiento de pertenencia que los hace sentir identificados con ese grupo (identidad social). Cuando existe una identificación con los objetivos comunes, y la acción social y la interacción están coordinadas en función de la defensa de los intereses del colectivo, todas las condiciones están dadas para la formación de grupos ideológicos. Los grupos dominantes intentarán desarrollar una ideología que permita la permanencia y reproducción de su dominación, mientras que la ideología de los grupos dominados servirá como base para sus prácticas y discursos de resistencia.

La necesidad económica fue la causa principal del establecimiento legal de la esclavitud en todas las colonias británicas de América del Norte para el año 1750. La creencia de la inferioridad racial e incivilización de los esclavos africanos permitió que esta práctica fuera aceptada. La esclavitud fomentó estereotipos duraderos que han afectado a la comunidad negra. De manera general los 
negros fueron catalogados como criminales y brutos. Particularmente, las mujeres fueron asociadas con la bestialidad en contraste con la imagen de pureza que poseía la mujer blanca.

La esclavitud provocó la división entre hombres y mujeres de descendencia africana. Debido a los valores patriarcales de la cultura africana, existe la opinión que la esclavitud fue menos perjudicial para las mujeres que para los hombres, porque al tener que obedecer las órdenes del amo blanco perdieron su hombría y libre albedrío. Empero, durante la esclavitud la mujer negra fue oprimida sexualmente, violada, forzada a reproducirse, y obligada a atender las tareas domésticas (Hooks, 1981).

Aun después de la abolición de la esclavitud, luego de la victoria de la Unión en la Guerra de Secesión la discriminación racial continuó, principalmente al sur de los Estados Unidos donde la segregación racial tenía su máxima expresión en las leyes de Jim Crow? ${ }^{7}$ El Movimiento por los Derechos Civiles surgió en los años sesenta del siglo XX como una respuesta pacífica pero contundente a estas medidas.

Dentro de este movimiento existía una lucha interna llevada a cabo por las mujeres estadounidenses de descendencia africana contra la doble discriminación que ellas enfrentaban por ser negras y por ser mujeres. Ellas tenían igual situación crítica de desempleo, pobreza, y segregación como sus compañeros. Como las mujeres blancas, ellas eran víctimas de la división sexista del trabajo y recibían un salario menor que el de los hombres a cambio de la misma labor. Además, debido a su género eran obligadas a desempeñar el papel tradicional de esposas y madres.

Por otra parte, los estereotipos fomentados por la esclavitud hacían imposible que el hombre negro tuviera un trabajo donde pudiera ganar lo suficiente para mantener a su familia como demanda la sociedad patriarcal. Como consecuencia la mujer negra comenzó a laborar fuera del hogar y a ganar un sueldo para sostenerlo. En la mayoría de los casos ellas tenían que dejar a sus hijos en casa para hacerse cargo de los hijos y los hogares de las mujeres blancas. Sin embargo, la independencia económica de la mujer negra (matriarquía negra) fue valorada negativamente como detrimento para la masculinidad y la comunidad negras.

Producto de su posición interseccional las mujeres negras fueron ignoradas por el Movimiento Feminista y el Movimiento de los Derechos Civiles en los años sesenta. A pesar de su compromiso y del apoyo indispensable de las mujeres negras al Movimiento de los Derechos Civiles, este solo se enfocó en la opresión de los hombres negros. Muchas mujeres negras se enfrentaron a las tendencias misóginas del Nacionalismo Negro.

La segunda ola feminista se concentró en los problemas de las mujeres blancas y prácticamente no dedicó alguna atención a los problemas de clase de la mujer negra. Las llamadas "experiencias universales de las mujeres" hacían caso omiso a la difícil posición de las mujeres negras debido a las diferencias raciales y sociales con las mujeres blancas. Asimismo, las mujeres negras estadounidenses no podían participar

(1) Las leyes de Jim Crow fueron leyes estaduales y locales en los estados sureños y los fronterizos que fue puesta en vigor entre 1876 y 1965. Obligaban a un status "igual pero separados" para los negros norteamericanos. (Enciclopedia Británica 2008). 
en paneles. Tampoco tenían la representación adecuada en los Departamentos de Estudios de la Mujer (Wong, 2014).

Por estas razones las mujeres negras no tuvieron otra opción que crear un movimiento propio con el objetivo de sensibilizar a los hombres negros sobre los problemas de género, y a las mujeres blancas sobre los asuntos raciales. De esta manera el Movimiento Feminista Negro se convirtió en el motor impulsor de la lucha contra la discriminación racial y la discriminación de género. Su objetivo era desarrollar una teoría que de una manera efectiva dirigiera la atención hacia la forma en que raza, género, y clase estaban profundamente vinculados a sus vidas.

Con el paso del tiempo, la resistencia de la mujer negra, surgida a partir de las injusticias durante el periodo de la esclavitud, comenzó a formar parte de su sabiduría, que permitió el desarrollo de su dignidad, fortaleza, independencia e imaginación. Como las mujeres negras trabajaron unidas en la búsqueda de su emancipación surgió la tradición de narrar historias donde se valoran experiencias vividas y concretas, así como germinó la hermandad y sentido de comunidad de las mujeres con descendencia africana (Hill Collins, 1990).

Su noción de comunidad es diferente a la de la cultura dominante, que aprecia la misma como una estructura arbitraria y débil creada por la competencia y la dominación. Como consecuencia de su sentido de la unidad ante la lucha, "los modelos afronorteamericanos de comunidad fortifican las relaciones interpersonales, la atención al prójimo, y la responsabilidad personal"2 (Hill Collins, 1990).

Para las mujeres negras la comunidad es una estructura que las empodera y que sirve como apoyo frente a la opresión de raza, género, y clase que ellas enfrentan. Sus funciones dentro de la comunidad la fortalecen. Las relaciones de poder son siempre positivas. El poder como energía resultante de los actos de resistencia, se utiliza para el bienestar de la comunidad.

La exclusión de las mujeres negras de los discursos feministas y antirracistas en los años 60 trajo como consecuencia el surgimiento del Movimiento Feminista Negro, totalmente comprometido en la lucha contra los diferentes y simultáneos tipos de opresión que ellas enfrentan. Al principio el movimiento tuvo muchos retos, algunos de ellos continúan en la actualidad. Tenía que convencer a las mujeres afronorteamericanas que el feminismo las incluía a ellas también. También, demandaba la aceptación de la diversidad y la distribución equitativa del poder entre las mujeres blancas y las negras. Finalmente, el feminismo negro tenía como objetivo la eliminación de las tendencias misóginas de los grupos antirracistas afronorteamericanos como el Nacionalismo Negro.

Entre las intelectuales feministas negras sobresale Alice Walker por su introducción del concepto "womanism" ("mujerismo"), que abarca toda la ideología y la práctica del feminismo de las mujeres negras (King, 2002). Según Walker (1983), una mujerista "reconoce las experiencias particulares y la herencia cultural de las mujeres negras, resiste los sistemas de dominación y aboga insistentemen-

(2) Todas las citas han sido traducidas por la autora. 
te por la liberación y la libre determinación de todas las personas".

El pensamiento feminista negro ha insistido en que "el cambio de conciencia del individuo y la transformación de las instituciones económicas y políticas constituyen ingredientes esenciales para el cambio social" (Hill Collins, 1990). Bell Hooks, otra destacada feminista negra, plantea que el feminismo en vez de solo luchar por el fin del machismo, debería "erradicar la ideología de dominación presente a todos los niveles de la cultura occidental" (Hill Collins, 1990).

Las feministas negras han criticado cómo la cultura afronorteamericana y muchas de sus costumbres patriarcales oprimen a las mujeres, principalmente el abuso emocional y físico provocado por sus padres y esposos. Sin embargo, las feministas negras sienten el deseo paralelo, como miembros de un grupo oprimido, de ensalzar la relevancia de su cultura y tradiciones afronorteamericanas. Por consiguiente, dentro del grupo de feministas negras existe una identidad colectiva basada en la percepción de compartir una herencia común dentro de la comunidad negra como grupo racial particular (identidad racial).

De acuerdo con Hill Collins (1990), las personas experimentan y resisten la opresión en tres niveles diferentes: el nivel sistémico de las instituciones; el nivel comunitario del contexto cultural creado por la raza, el género, y la clase; y finalmente el nivel de la biografía (experiencias concretas). Las feministas negras consideran estos tres niveles como lugares de dominación y de resistencia. Hill Collins (1990) también ha identificado tres temas recurrentes del pensamiento feminista negro: la atención a la naturaleza común de las opresiones de raza, clase y género, la conciencia de la herencia cultural que ha permitido la resistencia de las mujeres negras a estos tipos de discriminación, y la afirmación de las autodefiniciones y las autovaloraciones.

La afirmación de autodefiniciones y autovaloraciones enfatiza la importancia de que las mujeres afronorteamericanas "establezcan imágenes positivas tanto individuales como colectivas, que descubran sus propias perspectivas sobre las circunstancias de sus vidas, y que apliquen sus propios estándares de belleza, pensamiento y acción" (King, 2002). Esta afirmación de autodefiniciones y autovaloraciones será el aspecto en el cual nos basaremos para emprender el primer acercamiento al Análisis Crítico del Discurso de algunos enunciados de la novela The Help.

\section{MATERIALES Y MÉTODOS}

Primer acercamiento al análisis crítico del discurso de algunos enunciados de la novela The Help.

Van Dijk (1999) define el Análisis Crítico del Discurso como "un tipo de investigación analítica sobre el discurso que estudia primariamente el modo en que el abuso de poder social, el dominio y la desigualdad son practicados, reproducidos y ocasionalmente combatidos por los textos y el habla en el contexto social y político" (p.23).

El discurso literario tiene una función poética y una función comunicativa. Consecuentemente, existe un grado de emotividad en el discurso literario. El discurso literario es modal y los autores, como sujetos de la enunciación, utilizan a los personajes como agentes ilocutivos, que expresan valoraciones, apreciaciones y jerarquizaciones sobre objetos del mundo en conformidad con el lugar y el contexto sociocultural (Ayala, 2004, p.35). 
Los estudios de Leandro Caballero sentaron las bases para el análisis de las Categorías Semánticas Modales en la Facultad de Lenguas Extranjeras de la Universidad de La Habana. El Grupo de Estudios Semánticos y de Análisis de Discurso Leandro Caballero ha realizado un estudio profundo de la modalidad y se ha enfocado principalmente en las siguientes categorías semánticas modales: Valoración, Interés, Lealtad, Afectividad, Certidumbre y Expresividad. Esta investigación solo utiliza las categorías valoración, certidumbre y expresividad, cuyas definiciones por Galbán Pozo (2003) se presentan a continuación:

La valoración es la categoría semántica modal que expresa "la posición subjetiva e intencional ante lo dicho sobre la base de normas sociales en que se toma en cuenta el valor pragmático de los objetos y fenómenos que clasifican en una escala de valores axiológicos o paramétricos" (p. 37).

La certidumbre expresa "la posición subjetiva ante lo dicho sobre la base de la seguridad como valor pragmático, que se traduce en la perspectiva cognoscitiva-discursiva como conocimiento seguro, claro y evidente de las cosas, y en la perspectiva volitiva a partir de la firmeza o determinación como valor pragmático en que se sustenta el aspecto volitivo de las acciones del sujeto" (p.56).

Finalmente, la expresividad refleja "la posición subjetiva ante lo dicho acerca de los objetos y fenómenos de la realidad poniendo de manifiesto el estado emocional del hablante ante estos en una doble perspectiva, a saber, la del modo de expresión caracterizada por la oposición de los contrarios desbordamiento - contención y la del tono emocional expresado, que refleja la oposición de los contrarios satisfacción - insatisfacción" (p.84).
En el Grupo de Estudios Semánticos y de Análisis de Discurso Leandro Caballero se estudian las cuatro dimensiones en las que se analizan las categorías semánticas modales: la modal, la ilocutiva, la referencial, y la constructiva-gramatical. Esta investigación solo trabajó con la modal y la ilocutiva. Para la muestra se han seleccionado algunos enunciados (unidad de investigación) del personaje Minny como agente ilocutivo del discurso.

De un corpus de 30 enunciados de un mismo actante ilocutivo, se seleccionaron 14 para la muestra. Los enunciados fueron divididos en actos de habla que se clasificaron según la dimensión ilocutiva, el dominio y el valor axiológico. A continuación, se procedió a la determinación de los atributos relacionados a la certidumbre y la expresividad.

Actante ilocutivo y sujeto valorador: Minny Jackson es una sirvienta negra vivaz, madre de cinco hijos (Leroy Junior, Sugar, Felicia, Kindra, and Benny), y un sexto en camino, y esposa de Leroy, un hombre abusador y alcohólico. Esta fuerte y robusta mujer, relativamente joven, trabaja fuera de su casa durante todo el día, cocinando y limpiando en las casas de familias blancas de clase media en Jackson, Mississippi. Y cuando termina su trabajo, tiene que hacer las labores de su hogar, y tiene tiempo aun para participar en las actividades de su iglesia y ayudas a sus amigas también sirvientas. Minny es una excelente cocinera, pero su rasgo más relevante es su rebeldía. No tiene miedo decir lo que piensa, aun a costa de perder su trabajo. Esto la hace poco popular entre sus empleadores blancos. No sin dudarlo antes, decide participar en la escritura de un libro que denuncia las injusticias que enfrentan las sirvientas negras en Mississippi. 
A continuación, se ilustra el análisis realizado con tres ejemplos de enunciados:

\section{Enunciado 1.}

Contexto situacional: Minny perdió su empleo y busca desesperadamente uno en la casa de Mrs. Celia Rae Foote. Piensa que no tiene muchas oportunidades de trabajar allí debido a su mala reputación como sirvienta. Su empleadora anterior les dijo a todos que ella era una ladrona. Por lo tanto, piensa que Celia está evitando contratarla.

(I) - "I look down at my hundred-and-sixty-fivepound, five-foot-zero self practically busting out of my uniform. (II)- Too much for me?" (p.42).

El primer acto de habla es una apreciación de dominio físico y estético con valor axiológico positivo. Los atributos modales relacionados a la expresividad y la certidumbre muestran que en cuanto a la perspectiva cognoscitiva-discursiva el agente presenta seguridad. La perspectiva volitiva indica convencimiento y decisión. El modo de expresión indica que el agente no es contenido y está satisfecha pero perpleja, según el tono emocional. El segundo acto una evaluación normativa simple no prescriptiva con valor axiológico ambivalente. La perspectiva cognoscitiva-discursiva indica seguridad y la volitiva, convencimiento y decisión. El modo de expresión es desbordado y el tono emocional muestra tanto satisfacción como insatisfacción e irritamiento.

La estructura de superficie hace creer que Minny está insatisfecha consigo misma, sin embargo, el objeto de su insatisfacción es la empleadora. Debido a su experiencia Minny se considera una mujer eficiente y acostumbrada al trabajo duro. Si se trata de trabajo, Minny tiene una opinión positiva sobre ella misma y niega la existencia de tareas difíciles para ella. Se sorprende y casi le ofende que alguien piense que haya algo que ella no pueda hacer. Por este motivo su evaluación es ambivalente y reacciona de manera expresiva y desbordada.

\section{Enunciado 2}

Contexto situacional: Su esposo Leroy llega borracho a la casa en la madrugada, y quiere saber el secreto: el libro que Minny y sus amigas están escribiendo. Leroy trata de desper-tarla, pero Minny finge seguir durmiendo, pues teme que él quiera comenzar una pelea. Cuando él deja de molestarla, le da gracias a Dios por estar embarazada, pues es la única razón por la cual él no le pega. Entonces piensa sobre ella y su imagen ante la gente.

(I) -"They think big strong Minny, she sure can stand up for herself. (II)- But they don't know what a pathetic mess I turn into when Leroy's beating on me. (III)- I'm afraid to hit back. (IV)I'm afraid he'll leave me if I do. (V)- I know it makes no sense and I get so mad at myself for being so weak." (p.485).

Todos los actos de habla son apreciaciones con dominio físico, psicológico, ético, moral e ideológico, principalmente. Aunque el primer acto de habla tiene valor axiológico positi-vo, predomina el negativo en el enunciado. El modo de expresión es contenido aunque en el último acto de habla deja de serlo. El tono emocional indica insatisfacción y depresión. La perspectiva cognoscitiva-discursiva muestra incertidumbre y la volitiva, indecisión.

La personalidad de Minny está caracterizada por su complejidad. Primero, ella se valora positivamente como una persona fuerte, inquebrantable, que defiende sus ideas y que puede hacer cualquier tarea como sirvienta, 
madre, y miembro de la comunidad. La misma comunidad la valora como una heroína (They think big strong Minny). Sin embargo, cuando se trata de su relación con su esporo Leroy, Minny se siente completamente vulnerable e indefensa, y su autovaloración es negativa. Leroy ejerce su poder por medio de la violencia para mantener control sobre su mujer. Esta es una situación típica de violencia doméstica en la cual la figura controladora promueve la opresión interna de la mujer, que se expresa en autovaloraciones negativas y/o ambivalentes del dominado. Minny sabe que ella puede hacerle frente y defenderse, pero muestra incertidumbre porque teme que él la deje, y esto significaría la falta de una entrada económica y luchar con los obstáculos de ser una madre soltera afronorteamericana de cinco (seis) hijos.

\section{Enunciado 3.}

Contexto situacional: Aunque Minny no quiere que nadie lo sepa, a ella le gusta contar historias porque siente que está haciendo algo importante por la causa afronorteamericana.

(I)-"But truth is, I don't care that much about voting. (II)-I don't care about eating at the counter with white people. (III)-What I care about is, if in ten years, a white lady will call my girls dirty and accuse them of stealing the silver." (p.256).

Todos los actos de habla son apreciaciones con dominio ideológico. Los dos primeros actos de habla tienen valor axiológico negativo, pero el tercero es positivo. El modo de expresión es contenido. El tono emocional es de insatisfacción. La perspectiva cognoscitiva-discursiva muestra certidumbre y la volitiva, decisión.

Quizás Minny no se involucre de hecho en el Movimiento por los Derechos Civiles.
No obstante, sucesos cruciales durante el curso de la novela tienen una influencia indirecta en las acciones de Minny. Esto es evidente en su decisión de participar en la escritura del libro. Brindar sus cuentos le proporciona un sentimiento de empoderamiento y esperanza por un futuro mejor; pero las razones reales detrás de sus acciones no son las principales demandas del Movimiento. Sin lugar a duda el derecho al sufragio y el fin de la segregación son objetivos de primordial importancia; sin embargo, estos no se traducen en una eliminación instantánea de las prácticas discriminatorias. Esa es la razón por la cual Minny dice que su objetivo real es el cambio de conciencia el que podría beneficiar el futuro de sus hijas y de generaciones de mujeres negras en el futuro.

\section{RESULTADOS}

\section{Caracterización del sujeto valorador:}

Minny realiza principalmente apreciaciones que son éticas, morales, ideológicas y psicológicas. Desde el punto de vista axiológico, los enunciados son esencialmente negativos. De manera general, el discurso de Minny la hace decidida, segura de sí misma, desbordada e insatisfecha. Pero son características que cambian según el objeto de la valoración. Cuando el orden social es el objeto de la valoración, sus enunciados muestran su certidumbre e insatisfacción, incluso miedo. Cuando ella es el objeto de la valoración en cuestiones laborales o sociales, realiza apreciaciones en un $91 \%$ y estas son de dominio practico (36\%), ético, moral (63\%), and físico (11\%). Desde el punto de vista axiológico Minny es (87\%). Muestra seguridad (91\%), decisión (91\%), desbordamiento (91\%) e insatisfacción (82 $\%)$ en su relación con sus empleadoras. Estos valores cambian cuando se valora 
ella dentro de su relación marital. Aumentan las apreciaciones éticas y morales a un 83 $\%$, las ideológicas representan un $75 \%$ y las psicológicas predominan con $92 \%$. Sus apreciaciones son principalmente negativas (75\%) y ambivalentes (23\%). Disminuye su seguridad (67\%) y decisión (42\%), es menos expresiva (42\%) y su insatisfacción aumenta (99\%) cuando expresa su ira y agonía.

\section{DISCUSIÓN}

El análisis de los enunciados emitidos por Minny como sujeto emisor de discurso revela la existencia de valoraciones ambivalentes. Se valora positivamente y con certidumbre como madre, sirvienta doméstica y miembro de la comunidad. Sin embargo, en cuanto a su relación de pareja, su autovaloración es negativa y muestra incertidumbre, situación común cuando se es víctima de violencia doméstica. Por su experiencia de vivir y trabajar en un ambiente racista, Minny ha desarrollado sus propios puntos de vista sobre la lucha de los afronorteamericanos. A pesar de no estar involucrada directamente en el Movimiento por los Derechos Civiles, ella está comprometida con la lucha, y aplica sus propios estándares de pensamiento y acción para retar la ideología dominante. Minny defiende sus principios y no duda al emitir valoraciones negativas hacia lo que ella considera que es incorrecto. En muchos casos sus valoraciones muestran una expresividad desbordada.

Resulta necesario resaltar la posible equivalencia entre la perspectiva volitiva y el modo de expresión, debido a que muestran los mismos porcentajes en enunciados con diferentes objetos de la valoración.

\section{CONCLUSIONES}

El discurso es una forma de práctica social que refleja y modifica el orden social por me-dio del uso del lenguaje, de la comunicación de creencias e interacción en situaciones so-ciales. La interdisciplinariedad del Análisis Crítico del Discurso explora la relación entre las prácticas discursivas y las estructuras socioculturales, al tratar específicamente con la legitimación de la desigualdad social por medio del uso de la lengua. Indudablemente las ideologías juegan un papel de gran importancia no solo en la legitimación del abuso de poder, sino también en el empoderamiento de los grupos dominados, quienes desafían el orden establecido. La ideología feminista negra es la base del movimiento Feminista de las Mujeres Negras, lo que conlleva un compromiso activo por luchar en contra de la opresión simultánea que enfrentan las mujeres afronorteamericanas, e insiste en que tanto el cambio de conciencia individual como la transformación social de las instituciones económicas y políticas son elementos primordiales para el cambio social.

En este artículo se han presentado los resultados de una investigación que ha tenido como base teórica los estudios sobre el discurso, la ideología, el análisis crítico del discurso, la modalidad y el empleo de categorías semánticas modales para caracterizar a sujetos valoradores en el discurso literario. El estudio se enfocó en el desarrollo del feminismo negro como ideología y precisó de un estudio de la bibliografía para presentar un panorama de la historia de los afronorteamericanos en los Estados Unidos y así comprender las causas de las varias formas de discriminación que enfrentan las mujeres negras y los estereotipos creados para legitimar estas prácticas discriminatorias, especialmente en los estados sureños. 
The Help, la obra analizada escrita por Kathryn Stockett, tiene como contexto Mississippi en la década del 60 durante el Movimiento por los Derechos Civiles en los EEUU. Se estudiaron solamente en esta investigación las dimensiones ilocutiva y modal. El personaje de Minny fue escogido para proceder a su análisis como actante ilocutivo y sujeto valorador, tomando en cuenta las categorías semánticas modales de certidumbre y expresividad. Esta investigación refleja cómo el sujeto de la enunciación, la autora, utiliza a Minny como agente para describir el ambiente segregacionista y la realidad sociocultural de la época. El análisis del sujeto emisor de discurso, Minny, desde una perspectiva de las feministas negras, permitió conocer más sobre la posición de intersección de la discriminación de clase, raza y género de las mujeres afronorteamericanas. Por lo tanto, sería posible decir que su discurso refleja el comienzo de cambio de ideología de la mujer sureña afronorteamericana en los años 60 del siglo XX.

Los resultados de este estudio abrieron el camino a otras inquietudes investigativas relacionadas a la interseccionalidad en el discurso literario y la influencia del imaginario racial del sujeto de la enunciación, análisis que ya se están llevando a cabo por la autora del presente artículo.

\section{REFERENCIAS BIBLIOGRÁFICAS}

Ayala, I. M. (2004). A Characterization of the Feminine Valuating Subject in Alice Walker's Stories. Unpublished doctoral thesis. University of Havana, School of Foreign Languages

Curbeira, A. (2003). Lecturas de Semántica I. La Habana: Editorial Félix Varela.

Fairclough, N. (2003). Analyzing Discourse and Text: Textual Analysis for Social Research. London : Routledge.
Foucault, M. (1970). L'ordre du discours. Paris : Éditions Gallimard

Galván Pozo, A. M. (2003). Aproximación al estudio de las categorías semánticas modales (valoración, lealtad, certidumbre, interés, afectividad y expresividad) y su expresión a través de verbos de las lenguas españolas y alemanas. Tesis en opción al grado científico de Doctor en ciencias Filológicas. Ciudad de la Habana.

Hill Collins, P. (1990). Black Feminist Thought: Knowledge, Consciousness, and the Politics of Empowerment. New York: Routledge

Hill Collins, P. (1992). Race, Class, and Gender: An Anthology. Belmont, CA: Wadsworth Publishing Co.

Hooks, B. (1981). Ain't I a woman: black women and feminism. New York: Routledge.

King, D. (2002). Black Women and Feminism. Women's Studies Encyclopedia. Retrieved March 11, 2015, from http://www.gem. greenwood.com/wse/wse.jsp.

Stockett, K. (2009). The Help. New York: The Berkley Publishing Group.

Walker, A. (1983). In Search of Our Mother's Gardens. Florida: HBJ.

Van Dijk, T. A. (1993). Principles of critical discourse analysis. Discourse y Society, 4 (2), 249-283.

Van Dijk, T. A. (1998). Ideology. A Multidisciplinary Approach. London: Sage

Van Dijk, T. A. (1999). El análisis crítico del discurso. Anthropos, 186(5), 23-36. 
Van Dijk, T. A. (2008). Discourse and context: a sociocognitive approach. Cambridge: Cambridge University Press.

Wong, A. (2014). Women raise their voices: A literary analysis of the novel The Help by Kathryn Stockett. Unpublished term paper, University of Havana, Havana.

Wong, A. (2015). Breaking the status quo in the novel The Help. Unpublished diploma paper, University of Havana, Havana. 